Article

\title{
Viewing Sports Online during the COVID-19 Pandemic: The Antecedent Effects of Social Presence on the Technology Acceptance Model
}

\author{
Chia-Jung Chang ${ }^{1}$, Bryan Cheng-Yu Hsu ${ }^{2, *(D)}$ and Mei-Yen Chen ${ }^{1, *(D)}$ \\ 1 Graduate Institute of Sport, Leisure and Hospitality Management, National Taiwan Normal University, \\ Taipei 10610, Taiwan; b01701215@gmail.com \\ 2 Department of Physical Education and Sport Sciences, National Taiwan Normal University, \\ Taipei 10610, Taiwan \\ * Correspondence: brynhsu@gmail.com (B.C.-Y.H.); meiyentw@ntnu.edu.tw (M.-Y.C.)
}

check for

updates

Citation: Chang, C.-J.; Hsu, B.C.-Y.; Chen, M.-Y. Viewing Sports Online during the COVID-19 Pandemic: The Antecedent Effects of Social Presence on the Technology Acceptance Model. Sustainability 2022, 14, 341. https:// doi.org/10.3390/su14010341

Academic Editors: Eloy

López Meneses, M. Rocío Bohórquez and Jesus Fernández Gavira

Received: 25 November 2021 Accepted: 23 December 2021 Published: 29 December 2021

Publisher's Note: MDPI stays neutral with regard to jurisdictional claims in published maps and institutional affiliations.

Copyright: (C) 2021 by the authors. Licensee MDPI, Basel, Switzerland. This article is an open access article distributed under the terms and conditions of the Creative Commons Attribution (CC BY) license (https:// creativecommons.org/licenses/by/ $4.0 /)$.

\begin{abstract}
The outbreak of COVID-19 in 2020 has posed several challenges to the sporting industry, caused by the change in behavior of sporting fans from purchasing event tickets to watching live broadcasts of events on the Internet. This study aims to gain a deeper understanding of fan behavior in this "new normal". It adopts a technology acceptance model (TAM) to explore the effects of social presence (SP) in the context of online viewing of professional sports. For this purpose, the authors conducted an online survey of viewers who watched NBA sports events on the Amazon Mechanical Turk website using the Together Mode feature of Microsoft Teams. We collected 209 valid questionnaires and performed a partial least squares structural equation modeling analysis. The results showed that the SP-TAM structural model has adequate predictive relevance, and SP has a statistically significant positive relationship with both perceived ease of use and perceived usefulness. The model was thus validated, contributing to the existing body of knowledge on emerging technologies such as the creation of a virtual audience in sports. The study's findings suggest that technology developers should focus on the effects of SP and emphasize practical functions to increase the use intention of sporting fans. Furthermore, professional sporting leagues should prioritize the use of virtual fan technology to optimize the viewing experience of their fans.
\end{abstract}

Keywords: professional sports; sporting events; customer behavior; Together Mode; virtual fans

\section{Introduction}

With the onset of COVID-19, almost every country proscribed the organization of public events, including all types of sporting events. The suspension of events worldwide had an unprecedented impact on the sporting industry and drastically changed consumer behaviors [1]. The National Basketball Association (NBA) was the first professional sporting league to announce a postponement of a scheduled event when one of its players, Rudy Gobert, contracted the virus in March 2020. This decision marked a turning point in attitudes, with major professional sporting leagues and even the 2020 Tokyo Olympic Committee actively suspending or postponing their events in the face of the pandemic [2].

Even as countries began to lift their stringent lockdowns, games were played in mostly empty venues or with a restricted audience size to ensure social distancing. However, sporting events without the physical presence of fans were deemed unsustainable [3]. Matches played behind closed doors significantly changed the character of professional sports, with the lack of a typical stadium atmosphere, including booing, applauding, and singing fans, making it difficult for professional sports leagues to engage with their supporters and changing how the latter interacted with the sport [4].

Following the restrictions imposed by governments in response to the pandemic, the organizers of professional sporting events switched to digital technologies and online broadcasting to sustain the patronage of matches [5]. This has led to the increasing 
introduction of integrated innovative technologies to enhance the attractiveness of broadcasting services and to provide fans with a novel and immersive viewing experience. Such emerging technologies include 360-degree unmanned aerial cameras, 5G live broadcasting, and multi-view real-time video playback, all of which enrich the viewing experience of broadcasted sports events for patrons. In addition, immersive experience technologies have been developed that combine projection and screen technology to create a virtual fan experience [6]. With spectators seeking an immersive sporting experience through the pursuit of strong interactions with their teams through personalized media tools [7], these innovations have enabled fans to maintain a closer psychological connection with players, teams, and professional leagues, enhancing not only their loyalty but also their sports consumption experiences [8].

The viewing of sporting events has therefore been transferred from an offline to an online space, and fans can now support their favorite teams via their computers, televisions, mobile applications, and other media [9]. In recognition of the need to reimagine ways to virtually connect fans with players, the NBA took the lead in using innovative technology to re-launch its matches, pioneering the access by the public to the "Bubble League" during its three-month event in Orlando [10], wherein all teams selected by the league and staff members were managed and centrally monitored virtually. To create a lively atmosphere, it set up at each venue LED screens that displayed about 300 fans watching the teams play by using the Together Mode function in Microsoft Teams [11], an app developed by Microsoft Corporation with chat, meeting, and task functions. This innovative function created the effect of a crowd watching the games as a shared virtual experience [11].

The theory of social perception helps to explain how the Together Mode feature enables users to feel as if they are face to face [12] while remaining in the safety of their homes. The virtually filled stands also allow players to experience the real-time reaction, energy, and support of their fans [11]. Viewers' desire and emotional engagement with other viewers during the NBA games via Together Mode can also be explained by social cognitive theory [13]. The motivation, including the sense of community and social interactions, enables viewers to realize valuable outcomes and goals [14].

Recent research on the development of professional sports explores how technology can be optimized to create a more attractive service and increase its acceptance by viewers $[9,15]$. The technology acceptance model (TAM) has been widely adopted by researchers to explore consumer intention to use technology and the decision mechanisms underpinning their behavioral intentions [16,17]. Sports-based research has proven the usefulness of TAM in predicting user behavior in the contexts of intelligent wearable devices [17], augmented reality technologies [15], and sports streaming apps [18]. However, virtual fan technologies such as Together Mode have only recently emerged in 2020, and the viewing experiences from the integration of online and offline fandom significantly differ from those gained from conventional technologies. Thus, the purpose of this study was to explore behavioral intentions of fans on using this innovative technology in the context of online sports viewing by proposing the following research questions: (a) how modified TAMs predict sporting fans' use intentions toward online viewing technologies, and (b) how the antecedent effects of SP on PEOU and PU improve forecasts and the acceptance intentions of virtual fan technology.

This study aims to explore the behavioral intentions of fans using a modified TAM to identify the impact of social presence (SP) by incorporating SP as an enhancing construct. It focuses on virtual fan technology with an emphasis on a sense of community and social interactions. As a representation of the feeling of togetherness in a shared space facilitated via media [19] similar to Together Mode, SP as an antecedent of TAM can improve forecasts for the acceptance of virtual fan technology.

To the best of our knowledge, this study is the first to examine fan behavior in the context of the viewing of sports events using virtual fan technology. It is important to integrate the consideration of psychological connections into the original TAM and constitutes an improvement over the TAM. In addition, there are more and more technologies that 
emphasize fan interaction and the virtual reality effect under the new normal resulting from the COVID-19 pandemic. It is therefore necessary to propose a theoretical framework which could improve forecasting for acceptance of online viewing technologies and stimulate more theoretical discussion and extensions on the issue of sport fan behavior. From a practical standpoint, our findings can therefore serve as a guide for marketers and developers in their creation of more effective strategies that increase the use of virtual fan technologies. In addition, professional sports leagues and sporting events organizers can draw on the results of the study to optimize their strategies and integrate innovative technologies during and after the COVID-19 pandemic.

\section{Literature Review}

\subsection{Technology Acceptance Model (TAM)}

According to reasoned action theory [20] and planned behavior theory (TPB), TAM offers a more systematic prediction of users' acceptance of technologies [21]. They explain that such acceptance of new technology is contingent on perceived ease of use (PEOU) and perceived usefulness (PU). While PEOU measures the ease with which a technology can be used, PU estimates the efficacy identified by users [22]. A meta-analysis on TAM demonstrates the validity and reliability of the model and reports a significant predictive power of more than $40 \%$ for use intention toward technological systems [23,24]. This study uses TAM as a theoretical framework to explore user intention to watch sporting events using intelligent technologies.

Davis, who co-developed TAM, hypothesizes that a user's attitude is influenced by PEOU and PU, with PEOU directly affecting PU [25]. Furthermore, the use or rejection of a technology mainly depends on the attitude toward such technology [25]. An extended version of TAM proposed by Davis and other scholars effectively explains user behaviors by showing that behavioral intention, being a more important component, could replace the attitude construct [26] (see Figure 1).

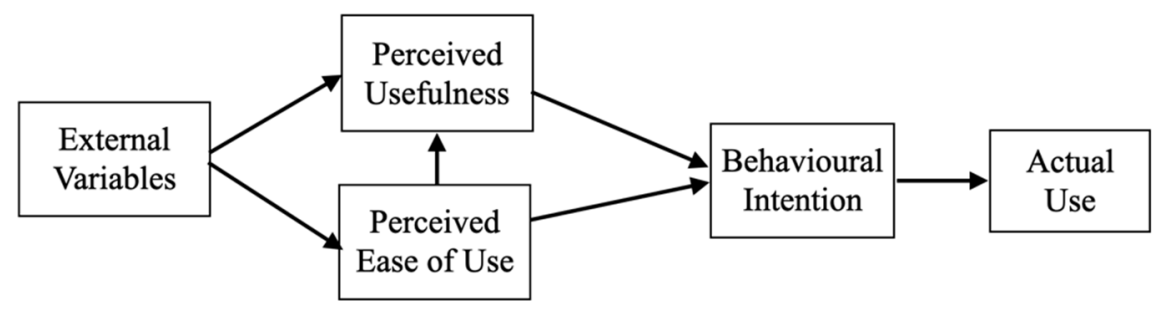

Figure 1. Final version of TAM by [26].

Although most studies using TAM explore technological systems from a utilitarian viewpoint, such as that of the workplace, the model has potentially wider applicability [27]. In recent years, an increasing number of researchers have applied TAM to hedonic activities in the field of sports (e.g., wearable devices, sports recording apps, and augmented reality technology) $[15,28]$. For example, Wu and Huang [18] use media richness as an antecedent and find that the modified TAM model has significant predictive power for use intention toward sports streaming apps. Other studies have also shown that adding corresponding external variables depending on the context of use helps increase the explanatory power of the integrated TAM [10].

This study discusses fan behavior in connection with watching NBA games via intelligent technology from a hedonic viewpoint. As Venkatesh and Morris [29] have argued, it is essential to understand the antecedents and potential effects on TAM to explain the use intention of a technology. However, TAM fails to account for systemic characteristics and other potential factors influencing users' technology acceptance [20].

\subsection{Social Presence}

Short, Williams, and Christie [30] were the first to propose the concept of social presence, which establishes that users who communicate via media tend to have psychological 
feelings that closely resemble those experienced in real settings. This degree of interaction is known as social presence, which emphasizes interactions and connections with people as well as human warmth and emotional and psychological connections in a mediated environment [31,32]. It also focuses on visual authenticity and social characteristics, which emphasize interaction with others. The objective of virtual reality (VR) technology, on the other hand, is to allow users to immerse themselves in another world [33] while coexisting and interacting with each other across spatial boundaries [34].

However, during a mediated interaction, users may want to experience togetherness without noticing the actual presence of technology [19]. The systematic review of SP undertaken by Oh et al. [32] found that the concept is often used in VR research, with researchers often utilizing the following conceptual variables to explain SP: visual representation, interactivity, and haptic feedback [32]. An increasing number of studies on sports-related technology media (e.g., sports websites and game broadcasting platforms) are using SP in view of the significant emphasis placed on social interactions and emotional communication within the sports industry. People with a highly social personality tend to be more willing to spend on sports [35].

Social TV research has also widely adopted SP [36-39]. Social TV viewing refers to the act of watching TV and communicating online with others who are simultaneously watching the same content [37]. Lim et al. [39] in their exploration of the impact of TV media on users' perceptions among individuals who watch sporting events via TV broadcasts find that media with stronger SP is positively related to user loyalty and commitment to such media. Kim and other scholars [37] also highlight the mediating effect of SP between social TV engagement and enjoyment; in other words, SP critically influences the positive emotions of virtual co-viewers of online sports events [37-39].

With the development of innovative viewing technologies such as Together Mode, both social TV viewing and virtual fan effects have been characterized by sociability and interaction. The viewing of sports events using Together Mode is contingent on VR technology, including the feeling of being immersed and visual representation. VR is an emerging medium that allows users to communicate face to face across spatial boundaries, changing the manner in which interpersonal interactions function. In the context of NBA games, Together Mode creates an interactive effect through its display of virtual fans alongside the court, rendering the experience more realistic. The Together Mode does not focus on information exchange but on "being with" other participants as well as sharing emotions and feedback. It creates an immersive experience and facilitates user interactions that reflect the connotations of SP [32].

\subsection{Social Presence with TAM and Hypotheses}

SP advocates certain psychological connections between users and technologies. In the context of sports watching, it can facilitate positive experiences such as enjoyment $[37,38,40]$ and even loyalty [39]. It also plays an influential role in a mediated environment and positively impacts user attitudes and behavioral intentions toward certain technologies [40]. Studies have found a positive correlation between the perception of warmth and the use of technology [41]. Thus, this study incorporates SP as an antecedent positively related with TAM in the context of the usage of Together Mode.

Research has highlighted the important role of SP in determining users' behavioral intentions in areas ranging from online shopping websites [31,42,43], computer-mediated conferences [44], and three-dimensional television (3DTV) [43] to online teaching [45]. The relationship between SP and PU has been widely investigated and established in an e-service context [31,42]. SP has also been shown to affect significantly users' perceptions of PEOU in online teaching systems [45]. In a 3DTV context, it promotes continuous adoption and directly and indirectly affects users' behavioral intentions [43].

The differences in early findings can be attributed to the varying nature of technologies and use contexts. Only a few studies have examined the relationship between SP and TAM in the context of the broadcasting of sporting events and fans' viewing behaviors [46]. It 
is thus worth exploring how virtual fans from different geographical locations who are displayed on an interface via Together Mode experience immersive feelings and how the use and functions of technology have significantly evolved, allowing users to do what was previously considered impossible.

Thus, we posit the following hypotheses (see Figure 2):

Hypothesis 1 (H1). The SP of watching NBA games is positively related to the PU of Together Mode.

Hypothesis 2 (H2). The SP of watching NBA games is positively related to the PEOU of Together Mode.

The study further proposes the following three hypotheses that are based on TAM theory (Venkatesh and Davis, 1996):

Hypothesis 3 (H3). The PEOU of Together Mode is positively related to the PU of Together Mode in the context of NBA game viewing.

Hypothesis 4 (H4). The PU of Together Mode is positively related to behavioral intentions toward Together Mode in the context of NBA game viewing.

Hypothesis 5 (H5). The PEOU of Together Mode is positively related to behavioral intentions toward Together Mode in the context of NBA game viewing.

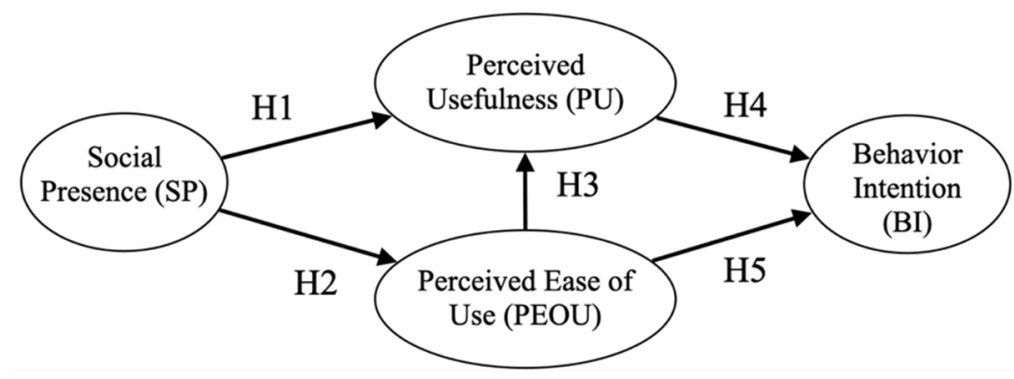

Figure 2. Proposed research framework.

\section{Method}

\subsection{Study Context and Data Collection}

In the study, we discuss the effects of SP in TAM in the context of online viewing of professional sports. The participants are individuals who use the Together Mode function in Microsoft Teams to watch live broadcasts of the NBA's regular season events. Since the Together Mode function in Microsoft Teams is currently only available to people in the United States and Canada, and considering the difficulty of collecting questionnaires during the epidemic, we conducted an online survey via Amazon Mechanical Turk for participants who watched NBA games in Together Mode during the 2020-2021 NBA season.

Amazon Mechanical Turk is a novel online survey platform with a charging function, an evaluation system, and validation processes comparable to those of traditional survey methods [47]. We also added a polygraph inspection tool including questions such as "Which team won the championship last season?" and "Which one is Microsoft Teams' icon?" to ensure data quality and confirm that participants had experience watching NBA games using the Together Mode function in Microsoft Teams and therefore met the research requirements.

We collected data on the Amazon Mechanical Turk platform during the period of 18-25 March 2021, and received a total of 209 valid questionnaires. Of the total sample, $55 \%$ were female and $45 \%$ were male; $24 \%$ were aged $30-39$ years and $23 \%$ were older than 60 years; $59 \%$ were single; $45 \%$ had a college education; and $26 \%$ held a graduate degree. 


\subsection{Instruments and Data Analysis}

The questionnaire was composed of two parts, with the first part documenting participant profiles and the second consisting of four validated scales used to measure the study's constructs. All items were measured on a five-point Likert scale, where 1 denotes "strongly disagree" and 5 "strongly agree". We adopted Lim et al.'s three-item SP scale [39], with a sample item being "I feel like I was physically communicating with others". We also used Venkatesh and Davis' TAM scales [26], which included a perceived usefulness scale (four items), with a sample item being "Using Microsoft Teams can provide better experience in watching NBA lives games", perceived ease of use scale (four items), with a sample item being "My interaction with Microsoft Teams is clear and understandable", and a behavioral intention scale (three items), with a sample item being "Assuming I have access to Microsoft Teams, I intend to use it to watch NBA games".

Sports-based studies have applied partial least square structural equation modeling (PLS-SEM) in various contexts $[48,49]$. Since it is suitable for studies with several constructs and for studies with small samples (i.e., $\mathrm{n} \leq 500$ ), it is better than covariance-based SEM for theory testing [50]. The technique takes a two-stage approach: in the first stage, the measurement model is assessed to confirm validity and reliability [51]; the second stage involves testing the hypothesis or the structural model [52]. This study also applied PLS-SEM using the SmartPLS 3.2.8 software to test the hypothesized relationships [53].

\section{Result}

\subsection{Measurement Model Assessment}

We assessed the internal consistency, convergent validity, and discriminant validity of the measurement model to confirm its reliability and validity. We examined the convergent validity of the constructs using factor loadings and average variance extracted (AVE) and internal consistency on the basis of the consistency reliability (CR) of the constructs $[52,53]$. Following Henseler, Ringle, and Sarstedt (2015) [54], we estimated the heterotrait-monotrait (HTMT) ratio of the constructs to establish discriminant validity. Tables 1 and 2 show that the loading of all items was greater than 0.7, except for SP3, and that the AVE of all constructs was higher than 0.5 , thus meeting the threshold for convergent validity. The $\mathrm{CR}$ of each construct was $0.844-0.864$, which confirms reliability. Finally, the HTMT values were under 0.9 , which establishes discriminant validity.

Table 1. Assessment of Reliability and Convergent Validity $(n=209)$.

\begin{tabular}{ccccc}
\hline Construct & Item & Loading & $\begin{array}{c}\text { Composite } \\
\text { Reliability }\end{array}$ & $\begin{array}{c}\text { Average Variance } \\
\text { Extracted (AVE) }\end{array}$ \\
\hline \multirow{2}{*}{ Social Presence (SP) } & SP1 & 0.856 & 0.844 & 0.647 \\
& SP2 & 0.871 & & \\
& SP3 & 0.671 & & 0.595 \\
Perceived Usefulness (PU) & PU1 & 0.762 & 0.855 & \\
& PU2 & 0.792 & & 0.614 \\
& PU3 & 0.742 & & \\
Perceived Ease of Use & PU4 & 0.789 & & \\
(PEOU) & PEOU1 & 0.804 & 0.864 & \\
& PEOU2 & 0.687 & & \\
& PEOU3 & 0.851 & & \\
\hline \multirow{2}{*}{ Behavioral Intention (BI) } & PEOU4 & 0.784 & & \\
& BI1 & 0.788 & 0.862 & \\
& BI2 & 0.879 & & \\
& BI3 & 0.796 & & \\
\end{tabular}


Table 2. Assessment of Discriminant Validity using HTMT $(\mathrm{n}=209)$.

\begin{tabular}{ccccc}
\hline Construct & SP & PU & PEOU & BI \\
\hline Social Presence (SP) & & & & \\
Perceived Usefulness (PU) & 0.663 & & & \\
Perceived Ease of Use (PEOU) & 0.624 & 0.552 & \\
Behavioral Intention (BI) & 0.870 & 0.892 & 0.633 \\
\hline
\end{tabular}

\subsection{Structural Model Assessment}

Prior to assessing the structural model, we examined for collinearity with the variance inflation factor (VIF) and found all values to be below the threshold of 3 [53], indicating that the model was free from common method bias [55]. Referencing Hair et al. [53], we employed a bootstrapping (5000 resamples) technique to test the hypotheses. Table 3 and Figure 3 show that all the paths in the model are statistically significant and that hypotheses $\mathrm{H} 1-\mathrm{H} 5$ are empirically supported.

Table 3. Assessment of Structural Model $(\mathrm{n}=209)$.

\begin{tabular}{ccccccc}
\hline Hypothesis & Relationship & $\mathbf{B}$ & $\boldsymbol{t}$-Value & $\mathbf{f}^{\mathbf{2}}$ & $\mathbf{R}^{\mathbf{2}}$ & $\mathbf{Q}^{\mathbf{2}}$ \\
\hline H1 & $\mathrm{SP} \rightarrow$ PU & 0.371 & $5.146^{* * *}$ & 0.151 & 0.301 & 0.232 \\
H2 & $\mathrm{SP} \rightarrow$ PEOU & 0.480 & $8.526^{* * *}$ & 0.300 & 0.237 & 0.215 \\
H3 & PEOU $\rightarrow$ PU & 0.263 & $3.643^{* * *}$ & 0.076 & & \\
H4 & PU $\rightarrow$ BI & 0.576 & $10.093^{* * *}$ & 0.565 & 0.521 & 0.361 \\
H5 & PEOU $\rightarrow$ BI & 0.256 & $4.317^{* * *}$ & 0.111 & &
\end{tabular}

Note: ${ }^{* * *} p<0.001$, NS (Not significant); SP: social presence, PU: perceived usefulness, PEOU: perceived ease of use, BI: behavioral intention.

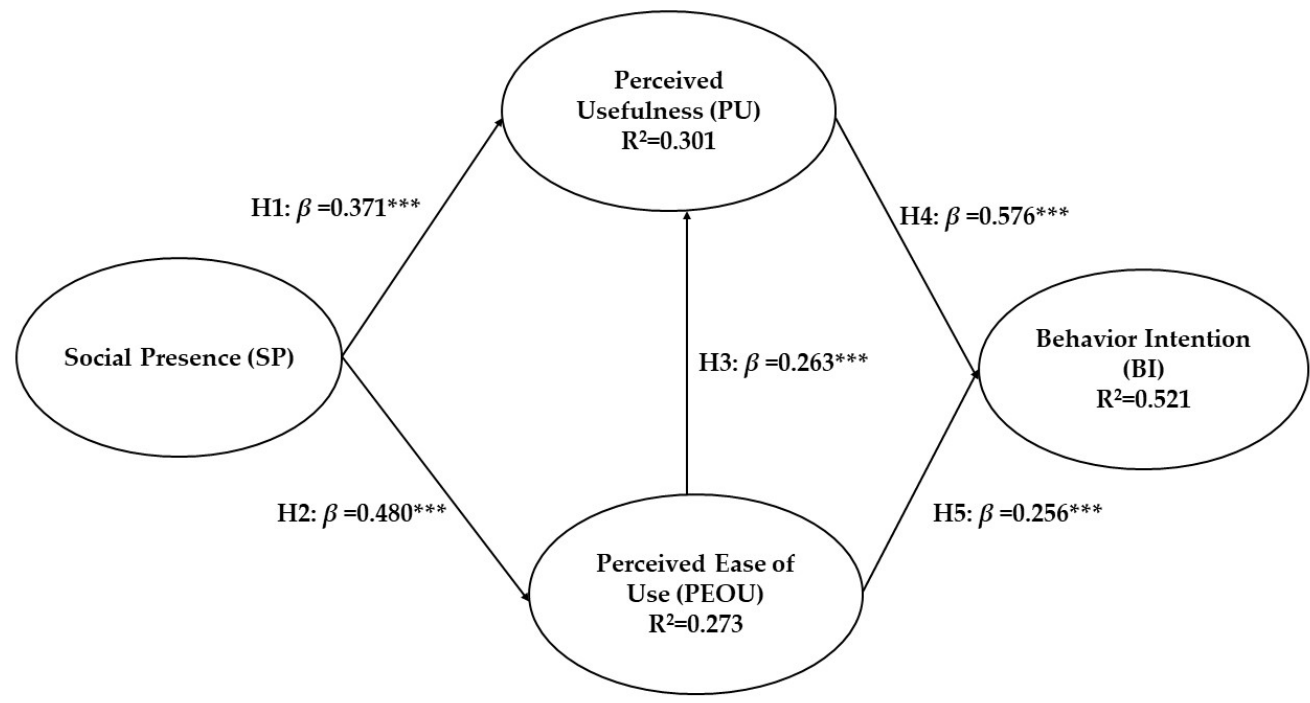

Figure 3. Structural Model Results. Note: (i) ${ }^{* * *} p<0.001$; (ii) SP: social presence, PU: perceived usefulness, PEOU: perceived ease of use, BI: behavioral intention.

We used the coefficient of determination $\left(R^{2}\right)$ to estimate explained variance. The $R^{2}$ values were $0.301,0.237$, and 0.521 , suggesting that the structural model reached adequate predictive relevance. To test the model's predictive ability, we employed a blindfolding approach to estimate $Q^{2}$. The $Q^{2}$ value for each construct was greater than zero, ensuring the model's predictive accuracy $[56,57]$.

\section{Discussion}

This study proposed SP-TAM in response to the lack of research on the effect of SP on TAM in the context of online sports viewing. It focuses on fans' viewing behaviors in the new normal resulting from the COVID-19 pandemic. First, the fit indexes show that 
the hypothesized SP-TAM is an appropriate model to predict sporting fans' use intentions toward online viewing technologies. All hypotheses were supported at the $p<0.05$ level. Both PEOU and PU had a positive significant effect on BI, a result which aligns with those of previous research and supports the original TAM $[26,45]$. Second, SP, the new antecedent variable, reported a positive significant effect on PEOU and PU, thus confirming the role of SP in Together Mode and in creating an immersive experience for sports fans. Further, SP influences the PEOU and PU of Together Mode, which strengthens behavioral intentions toward the innovative technology.

This study is theoretically significant because it extends SP research on fans' viewing behaviors. Although only a few SP-TAM studies have been conducted on virtual fan effects such as that of Together Mode, the relationship between SP and TAM has been verified in several contexts. Hassanein and Head [31] show that higher levels of social presence are shown to positively impact the perceived usefulness, enjoyment and trust of shopping websites. Ogonowski et al. [42] also found that social presence could influence trust in the website, but also participants' enjoyment and perceived usefulness of the site. This finding regarding the effect of SP on PU in the virtual fans online viewing context in this research re-echoes those of earlier studies in an e-services context, while the observation regarding the effect of SP on PEOU mirrors that of another earlier study undertaken in the context of online teaching [45].

Studies have proven the significant impact of SP on PU, although its influence on PEOU is seldom discussed in the e-services context. Research has also demonstrated the positive impact of SP on several constructs influencing the behavioral intentions of online consumers [42]. Smith and Sivo [45] show that perceived ease of use, perceived usefulness and social presence were all significant determinants of teachers' intent to continue using elearning. While SP has a significant positive influence on the PEOU of e-learning systems, it has a weaker impact on PU. In other words, the lack of SP negatively affects teachers' PEOU, and this may prevent them from adopting e-learning systems. In sum, the effect of SP on TAM constructs is contingent on the context and other variables used in the model [43].

This study suggests that SP has a significant positive effect on both PU and PEOU in the context of online sports viewing via Together Mode. Many users were loyal fans of the NBA and were thus more inclined to buy tickets to watch games offline rather than online. However, the COVID-19 pandemic and the subsequent lockdowns worldwide led to the temporary closure of several sports venues. A key characteristic of watching a match at a stadium is the atmosphere and the sense of community it promotes. Despite the obvious differences between watching a game offline and online, sports fans using Together Mode shared a common need for social interactions. They seem to have accepted the technology because it was one of the few options available that offered an immersive experience similar to that derived from offline sports events. Kim et al. [38] show that when people felt strong social presence, they enjoyed viewing experiences more, such as viewing sport game on social TV. Online viewing via Together Mode is accompanied by shared visual and auditory effects, and the virtual fan effect positively influences the PU of Together Mode. This explains the importance of SP and its impact on PU, a result aligned with those of most of the previous studies on online interfaces [31,42,43].

It is noteworthy that the effect of SP on PEOU is greater than that on PU. SP allows online technology users to have experiences similar to those of watching a game at the stadium. The Together Mode made it easier and more convenient to watch a game from home. Given the pandemic and its restrictions, fans felt safer indoors, and this has significantly influenced the research results.

A comparison of the coefficients reveals that PU is a stronger contributing factor than PEOU in users' behavioral intention toward Together Mode. This result corroborates that of previous research on the usefulness of, and behavioral intentions toward, technology $[15,58]$. Thus, PEOU affects behavioral intentions through PU, with PU having a stronger direct impact on behavioral intentions. In other words, users are more concerned about the 
actual functions of watching sports events on Microsoft Teams, such as visual and auditory experiences and interactivity.

This study shows the applicability of SP in the novel context of immersive experience technologies such as virtual fandom, revealing that SP significantly affects both PU and PEOU, which is contrary to those derived in other contexts [31,42,43]. We also report the results for each path of the extended TAM. It is recommended that sports events marketers prioritize SP since it is a key feature influencing virtual fan technology, particularly in the new normal created by the COVID-19 pandemic. Manufacturers of online viewing and VR technologies should also highlight the useful and social aspects of technological services.

\section{Conclusions}

\subsection{Theoretical and Practical Significance}

Although current studies have shown the crucial role of SP in forecasting users' behavioral intentions in several contexts [31,42-45], this study is the first to discuss fan behavior in the context of the viewing of sports games using virtual fan technology. This study applied SP-TAM as a theoretical framework to explain factors influencing fans' behavioral intentions toward using the Together Mode tool in Microsoft Teams to watch sports games online during the COVID-19 pandemic. The results reveal that all relationships in SP-TAM are statistically significant, and that hypotheses $\mathrm{H} 1-\mathrm{H} 5$ are fully supported in the context of online sports viewing. Starting from this fundamental understanding, future research can further investigate the complex interrelationships among social presence, TAM and other new variables to clarify the intricacies and thereby optimize fan sport viewing online experience.

The Together Mode creates a virtual fan effect and immersive experiences that are similar to watching sports in a stadium. The results show that both PU and PEOU have a significant positive effect on behavioral intentions. Thus, developers of related technologies should consider simplifying overall use processes and provide clear instructions to ease public use, increase acceptance of technologies, satisfy consumer needs, and expand the market. In addition, developers should emphasize actual functions, such as visual representation, interactivity, and playfulness and the experience of appearing on screen as a virtual fan during a match.

SP, as an antecedent of TAM, plays a major role in the virtual fan context. Thus, interactions and the feelings of warmth are key features of virtual technologies. There are several costs and restrictions associated with watching matches in a stadium. Further, the development of emerging technology with virtual reality has gradually shifted fans viewing behaviors from offline to online [59], and the COVID-19 pandemic has accelerated this transformation. Immersive experiences and interactions will become indispensable features in fans' online viewing behaviors. Thus, those responsible for developing the digital fan experience in professional sports should focus on SP, strengthen elements valued in the viewing experience, and reduce restrictions related to online viewing.

At the peak of the COVID-19 pandemic between 2019 and 2020, the NBA adopted virtual fan technology at the Orlando Stadium. While certain professional sports are gradually transitioning back to offline events, fans' stadium experiences have profoundly changed. Professional sports must be prepared for possible uncertainties.

In conclusion, this study explored fan behaviors toward online viewing and virtual fan technology. With fans accepting Microsoft Teams as an emerging medium for watching sports events and interacting with other fans, developers and professional sports organizers should prioritize SP features such as social interactions to optimize fans' viewing experience and create a favorable atmosphere at offline venues.

\subsection{Limitations and Future Research}

This study used self-reporting scales and administered questionnaire surveys via the Internet. Thus, it is possible that the results are subject to common method variance (CMV). Moreover, while the questionnaire was anonymous, there remain doubts about 
respondents' actual experiences and other common CMV problems. Second, because virtual fan technology has only recently emerged in the sports context, we focus on the relationship between SP and TAM. Previous studies, however, suggest that potential variables such as perceived enjoyment and flow experiences have a mediating or moderating effect on SP. Third, this study does not discuss the effects of various user groups as well as the previous use experiences of advanced technology and the level of sport fans' involvement. Future research could focus on the effects of these variables and examine their impact on SP and TAM. While these limitations and possible unknown interactions among the variables may reduce the reliability of our findings, future research could test this study's results using other methods to advance the existing knowledge regarding fans' viewing behaviors through virtual fan technology in the new normal.

Author Contributions: Conceptualization, C.-J.C. and M.-Y.C.; methodology, C.-J.C. and B.C.-Y.H.; software, B.C.-Y.H.; validation, M.-Y.C. and B.C.-Y.H.; formal analysis, B.C.-Y.H.; investigation, C.-J.C.; writing—original draft preparation, C.-J.C.; writing—review and editing, C.-J.C., B.C.-Y.H. and M.-Y.C.; visualization, C.-J.C. and B.C.-Y.H. project administration, C.-J.C. and M.-Y.C.; funding acquisition, M.-Y.C. All authors have read and agreed to the published version of the manuscript.

Funding: This research was funded by the Ministry of Science and Technology, Taiwan (MOST 105-2410-H-003-059-MY3).

Institutional Review Board Statement: The study was approved by the Center for Research Ethics, National Taiwan Normal University.

Informed Consent Statement: Informed consent was obtained from all subjects involved in the study.

Data Availability Statement: The full dataset presented in this study is available on request from the corresponding author.

Acknowledgments: This study was supported by the Ministry of Science and Technology, Taiwan (MOST 105-2410-H-003-059-MY3) and the "Higher Education Deep Cultivation Project" of the National Taiwan Normal University (NTNU), sponsored by the Ministry of Education, Taiwan.

Conflicts of Interest: The authors declare no conflict of interest.

\section{References}

1. Lis, A.; Tomanek, M. Sport management: Thematic mapping of the research field. J. Phys. Educ. Sport 2020, 20, 1201-1208.

2. Gilat, R.; Cole, B.J. COVID-19, Medicine, and Sports. Arthrosc. Sports Med. Rehabil. 2020, 2, e175-e176. [CrossRef] [PubMed]

3. Sheptak, R.D.; Menaker, B.E. When sport event work stopped: Exposure of sport event labor precarity by the COVID-19 pandemic. Int. J. Sport Commun. 2020, 13, 427-435. [CrossRef]

4. Drewes, M.; Daumann, F.; Follert, F. Exploring the sports economic impact of COVID-19 on professional soccer. Soccer Soc. 2021, 22, 125-137. [CrossRef]

5. Horky, T. No sports, no spectators-no media, no money? The importance of spectators and broadcasting for professional sports during COVID-19. Soccer Soc. 2021, 22, 96-102. [CrossRef]

6. Miah, A.; Fenton, A.; Chadwick, S. Virtual reality and sports: The rise of mixed, augmented, immersive, and esports experiences. In 21st Century Sports; Springer: Singapore, 2020; pp. 249-262.

7. Pirker, J. Video games, technology, and sport: The future is interactive, immersive, and adaptive. In 21st Century Sports; Springer: Singapore, 2020; pp. 263-273.

8. Chan-Olmsted, S.; Xiao, M. Smart sports fans: Factors influencing sport consumption on smartphones. Sport Mark. Q. 2019, 28, 181-194. [CrossRef]

9. Majumdar, B.; Naha, S. Live sport during the COVID-19 crisis: Fans as creative broadcasters. Sport Soc. 2020, 23, 1091-1099. [CrossRef]

10. Cho, S.; Shin, N.; Kwak, D.H.; Kim, A.C.H.; Jang, W.S.; Lee, J.S.; Ko, Y.J. The Impact of COVID-19 crisis on major spectator sport industry in the U.S. and South Korea: Challenges and outlook. J. Glob. Sport Manag. 2021, 1-25. [CrossRef]

11. NBA. NBA Playoffs 2020: How You Can Become a Virtual Fan and Support Your Team in the 'Stands'. Available online: https:/ / in.nba.com/news/nba-playoffs-2020-how-you-can-become-a-virutal-fan-watch-games-orlando-bubble/1943qou0 eri5f196xb-k9njptxp (accessed on 2 September 2020).

12. Microsoft Reimagining How NBA Fans and Teams Experience the Game of Basketball with Together Mode in Microsoft Teams. Available online: https://www.microsoft.com/en-us/microsoft-365/blog/2020/07/24/reimagining-teams-experiencebasketball-microsoft-teams/ (accessed on 24 July 2020).

13. Bandura, A. Social cognitive theory of mass communication. Media Psychol. 2001, 3, 265-299. [CrossRef] 
14. Hilvert-Bruce, Z.; Neill, J.T.; Sjöblom, M.; Hamari, J. Social motivations of live-streaming viewer engagement on Twitch. Comput. Hum. Behav. 2018, 84, 58-67. [CrossRef]

15. Goebert, C.; Greenhalgh, G.P. A new reality: Fan perceptions of augmented reality readiness in sport marketing. Comput. Hum. Behav. 2020, 106, 106231. [CrossRef]

16. Cardinale, M.; Varley, M. Wearable Training-Monitoring technology: Applications, challenges, and opportunities. Int. J. Sports Physiol. Perform. 2017, 12, S2-55-S2-62. [CrossRef]

17. Qi, W. A design exploration of intelligent wearable companion of smartphone for fitness and healthcare. Int. J. Pattern Recognit. Artif. Intell. 2019, 33, 1959023. [CrossRef]

18. Wu, H.C.H. A study on using the technology acceptance model to explore the behavioral intentions of consumers using APP to watch sports events. Phys. Educ. J. 2020, 3, 75-94.

19. Biocca, F.; Levy, M.R. Communication in the Age of Virtual Reality; Routledge: London, UK, 2013.

20. Fishbein, M.; Ajzen, I. Belief, Attitude, Intention, and Behavior: An Introduction to Theory and Research; Adison-Wesley: Reading, MA, USA, 1975. [CrossRef]

21. Marangunić, N.; Granić, A. Technology acceptance model: A literature review from 1986 to 2013. Univers. Access Inf. Soc. 2015, 14, 81-95. [CrossRef]

22. Davis, F.D.; Bagozzi, R.P.; Warshaw, P.R. User acceptance of computer technology: A comparison of two theoretical models. Manag. Sci. 1989, 35, 982-1003. [CrossRef]

23. King, W.R.; He, J. A meta-analysis of the technology acceptance model. Inf. Manag. 2006, 43, 740-755. [CrossRef]

24. Legris, P.; Ingham, J.; Collerette, P. Why do people use information technology? A critical review of the technology acceptance model. Inf. Manag. 2003, 40, 191-204. [CrossRef]

25. Davis, F.D. A Technology Acceptance Model for Empirically Testing New End-User Information Systems: Theory and Results; Massachusetts Institute of Technology: Cambridge, MA, USA, 1985.

26. Venkatesh, V.; Davis, F.D. A model of the antecedents of perceived ease of use: Development and test. Decis. Sci. 1996, 27, 451-481. [CrossRef]

27. Perienen, A. Frameworks for ICT integration in mathematics education-A teacher's perspective. Eurasia J. Math. Sci. Technol. Educ. 2020, 16, em1845. [CrossRef]

28. Byun, H.; Chiu, W.; Bae, J.-S. Exploring the adoption of sports brand apps: An application of the modified technology acceptance model. Int. J. Asian Bus. Inf. Manag. (IJABIM) 2018, 9, 52-65. [CrossRef]

29. Venkatesh, V.; Morris, M.G. Why don't men ever stop to ask for directions? Gender, social influence, and their role in technology acceptance and usage behavior. MIS Q. 2000, 24, 115. [CrossRef]

30. Parker, E.B.; Short, J.; Williams, E.; Christie, B. The Social Psychology of Telecommunications. Contemp. Sociol. A J. Rev. 1978, 7, 32. [CrossRef]

31. Hassanein, K.; Head, M. Manipulating perceived social presence through the web interface and its impact on attitude towards online shopping. Int. J. Hum.-Comput. Stud. 2007, 65, 689-708. [CrossRef]

32. Oh, C.S.; Bailenson, J.N.; Welch, G.F. A systematic review of social presence: Definition, antecedents, and implications. Front. Robot. AI 2018, 5, 114. [CrossRef] [PubMed]

33. Heeter, C. Communication research on consumer VR. Commun. Age Virtual Real. 1995, 1, 191-218.

34. Sallnäs, E.-L. Effects of communication mode on social presence, virtual presence, and performance in collaborative virtual environments. Presence Teleoperators Virtual Environ. 2005, 14, 434-449. [CrossRef]

35. Devlin, M.B.; Brown-Devlin, N. Using personality and team identity to predict sports media consumption. Int. J. Sport Commun. 2017, 10, 371-392. [CrossRef]

36. Brown-Devlin, N.; Devlin, M.B.; Billings, A.C.; Brown, K.A. Five rings, five screens? A global examination of social TV influence on social presence and social identification during the 2018 Winter Olympic Games. Commun. Sport 2020, 9, 865-887. [CrossRef]

37. Kim, J.; Merrill Jr, K.; Yang, H. Why we make the choices we do: Social tv viewing experiences and the mediating role of social presence. Telemat. Inform. 2019, 45, 101281. [CrossRef]

38. Kim, J.; Song, H.; Lee, S. Extrovert and lonely individuals' social TV viewing experiences: A mediating and moderating role of social presence. Mass Commun. Soc. 2018, 21, 50-70. [CrossRef]

39. Lim, J.S.; Hwang, Y.; Kim, S.; Biocca, F.A. How social media engagement leads to sports channel loyalty: Mediating roles of social presence and channel commitment. Comput. Hum. Behav. 2015, 46, 158-167. [CrossRef]

40. Wang, H.; Lee, K. Getting in the flow together: The role of social presence, perceived enjoyment and concentration on sustainable use intention of mobile social network game. Sustainability 2020, 12, 6853. [CrossRef]

41. Steinfield, C.W. Computer-Mediated communication in an organizational setting: Explaining task-related and socioemotional uses. Ann. Int. Commun. Assoc. 1986, 9, 777-804. [CrossRef]

42. Ogonowski, A.; Montandon, A.; Botha, E.; Reyneke, M. Should new online stores invest in social presence elements? The effect of social presence on initial trust formation. J. Retail. Consum. Serv. 2014, 21, 482-491. [CrossRef]

43. Shin, D. 3DTV as a social platform for communication and interaction. Inf. Technol. People 2012, 25, 55-80. [CrossRef]

44. Gunawardena, C.N.; Zittle, F.J. Social presence as a predictor of satisfaction within a computer-mediated conferencing environment. Am. J. Distance Educ. 1997, 11, 8-26. [CrossRef] 
45. Smith, J.A.; Sivo, S.A. Predicting continued use of online teacher professional development and the influence of social presence and sociability. Br. J. Educ. Technol. 2012, 43, 871-882. [CrossRef]

46. Chang, C.-J. Fan Behavior for Watching NBA Games during the COVID-19 Pandemic. Ph.D. Dissertation, National Taiwan Normal University, Taipei, Taiwan, 2021.

47. Buhrmester, M.; Kwang, T.; Gosling, S.D. Amazon's Mechanical Turk: A New Source of Inexpensive, Yet High-Quality Data? American Psychological Association: Washington, DC, USA, 2016.

48. Howat, G.; Assaker, G. The hierarchical effects of perceived quality on perceived value, satisfaction, and loyalty: Empirical results from public, outdoor aquatic centres in Australia. Sport Manag. Rev. 2013, 16, 268-284. [CrossRef]

49. Kim, S.; Morgan, A.; Assaker, G. Examining the relationship between sport spectator motivation, involvement, and loyalty: A structural model in the context of Australian Rules football. Sport Soc. 2021, 24, 1006-1032. [CrossRef]

50. Sarstedt, M.; Cheah, J.-H. Partial least squares structural equation modeling using SmartPLS: A software review. J. Mark. Anal. 2019, 7, 196-202. [CrossRef]

51. Sarstedt, M.; Ringle, C.M.; Hair, J.F. Partial least squares structural equation modeling. Handb. Mark. Res. 2017, $26,1-40$.

52. Hair, J.F., Jr.; Sarstedt, M.; Ringle, C.M.; Gudergan, S.P. Advanced Issues in Partial Least Squares Structural Equation Modeling; SAGE Publications: New York, NY, USA, 2017.

53. Hair, J.F., Jr.; Hult, G.T.M.; Ringle, C.M.; Sarstedt, M. A Primer on Partial Least Squares Structural Equation Modeling (PLS-SEM); SAGE Publications: New York, NY, USA, 2021.

54. Henseler, J.; Ringle, C.M.; Sarstedt, M. A new criterion for assessing discriminant validity in variance-based structural equation modeling. J. Acad. Mark. Sci. 2015, 43, 115-135. [CrossRef]

55. Kock, N. Common method bias in PLS-SEM: A full collinearity assessment approach. Int. J. e-Collab. 2015, 11, 1-10. [CrossRef]

56. Shmueli, G.; Ray, S.; Estrada, J.M.V.; Chatla, S.B. The elephant in the room: Predictive performance of PLS models. J. Bus. Res. 2016, 69, 4552-4564. [CrossRef]

57. Shmueli, G.; Sarstedt, M.; Hair, J.F.; Cheah, J.-H.; Ting, H.; Vaithilingam, S.; Ringle, C.M. Predictive model assessment in PLS-SEM: Guidelines for using PLSpredict. Eur. J. Mark. 2019, 53, 2322-2347. [CrossRef]

58. Rosly, R.M.; Khalid, F. Evaluation of the "e-Daftar" system using the Technology Acceptance Model (TAM). Creat. Educ. 2018, 9, 675-686. [CrossRef]

59. Pu, H.; James, J. The distant fan segment: Exploring motives and psychological connection of International National Basketball Association fans. Int. J. Sports Mark. Spons. 2017, 18, 418-438. [CrossRef] 